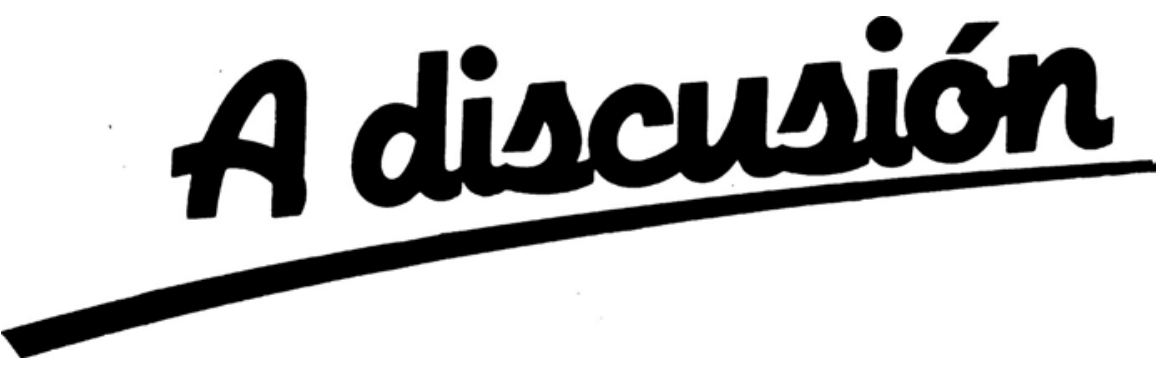

\title{
THE PROCESS FOLLOWED BY PPP DATA. ON THE PROPERTIES OF LINEARITY TESTS*
}

\author{
Ivan Paya and David A. Peel**
}

WP-AD 2005-23

Corresponding author: I. Paya. University of Alicante. Departamento Fundamentos Análisis Económico. E-mail: ivanpaya@merlin.fae.ua.es / Tel.: +34 965903614 / Fax: +34 965903898.

Editor: Instituto Valenciano de Investigaciones Económicas, S.A.

Primera Edición Junio 2005

Depósito Legal: V-3023-2005

IVIE working papers offer in advance the results of economic research under way in order to encourage a discussion process before sending them to scientific journals for their final publication.

\footnotetext{
* Ivan Paya acknowledged financial support from the Ivie.

** I. Paya: University of Alicante. D.A. Peel: Lancaster University Management School.
} 


\title{
THE PROCESS FOLLOWED BY PPP DATA. ON THE PROPERTIES OF LINEARITY TESTS
}

\author{
Ivan Paya and David A. Peel
}

\begin{abstract}
Recent research has reported the lack of correct size in stationarity test for PPP deviations within a linear framework. However, theoretically well motivated nonlinear models, such as the ESTAR, appear to parsimoniously fit the PPP data and provide an explanation for the PPP "puzzle". Employing Monte Carlo experiments we analyze the size and power of the nonlinear tests against a variety of nonstationary hypotheses. We also fit the ESTAR model to data from high inflation economies. Our results provide further support for ESTAR specification.
\end{abstract}

Keywords: ESTAR, Real Exchange Rate, Size, Linearity Test.

Journal of Economic Literature: C15, C22, F31. 


\section{Introduction}

A number of authors (see e.g. Dumas, 1992; Uppal, 1993; Sercu et al., 1995; Ohanian and Stockman, 1997; O'Connell, 1998; and Berka, 2002) have developed theoretical models which investigate the nature of the PPP adjustment process when agents face transactions costs or there are sunk costs of international arbitrage. They demonstrate that such factors induce nonlinear adjustment towards equilibrium PPP. Whilst globally mean reverting this nonlinear process has the property of exhibiting near unit root behavior for small deviations from equilibrium. Two parametric models that capture this type of nonlinear adjustment are the threshold autoregressive (TAR) model or the exponential smooth transition autoregressive (ESTAR) model. The models differ in that in the TAR model adjustment between regimes is assumed to occur abruptly whereas in the ESTAR model adjustment occurs smoothly. A smooth adjustment process is explicitly suggested in some theoretical models (e.g. Dumas, 1992; and Anderson, 1997). Also, as postulated by Terasvirta (1994), and demonstrated theoretically by Berka (2002), in aggregate data, regime changes may be smooth rather than discrete given that heterogeneous agents do not act simultaneously even if they make dichotomous decisions.

Empirical results suggest that TAR or ESTAR models produce parsimonious fits to a variety of different PPP data sets ${ }^{2}$ [see e.g. Balke and Fomby, 1997; Michael et al., 1997; Obstfeld and Taylor, 1997; Kilian and Taylor, 2003; and Paya et al., 2003]. These models also provide some explanation of the "Purchasing Power Parity puzzle" outlined by Rogoff (1996). ${ }^{3}$

In spite of the theoretical and empirical evidence in favour of a nonlinear specification there are a significant number of papers that suggest that PPP deviations may be explained by non-stationary linear or other nonlinear alternatives. For instance, Engel (2000) has shown, using artificial calibrated data from a linear structural model which embodies a permanent PPP component, that unit root (and cointegration tests) have serious size biases. The standard unit root tests reject the null hypothesis of a unit root too much, even when a substantial random walk component that accounts for $42 \%$ of an assumed 100

\footnotetext{
${ }^{2}$ Estimates of the nonlinear models have been reported employing data sampled at different levels of aggregation. For example, Taylor et al. (2001), report ESTAR models employing monthly data, Kilian and Taylor (2003) quarterly data whilst Micheal et al. (1997), and Paya and Peel (2003) report results employing annual data. Paya and Peel (2004) show that the empirical results obtained at different degrees of temporal aggregation are consistent with the nonlinear data generating process (DGP) obtained at the highest frequency observable (monthly).

${ }^{3}$ Rogoff drew attention to the fact that in linear models it is difficult to reconcile high shortterm volatility of real exchange rates with extremely slow convergence to PPP. The average reported half-life of PPP deviations based on linear models is around 3-5 years, seemingly far too long to be explained by nominal rigidities. An important property of the nonlinear models is that their impulse response functions show that whilst the speed of adjustment for small shocks around equilibrium can be extremely slow, larger shocks mean-revert much faster than the "glacial rates" obtained in the linear estimates (see e.g. Taylor et al., 2001, and Paya et al., 2003).
} 
year forecast variance is present. ${ }^{4}$ Bleaney et al. $(1999,2003)$ model PPP deviations $^{5}$ as a stochastic unit root process Others have modelled real exchange rates for developed and less developed economies as nonstationary but mean reverting fractional processes (see e.g. Diebold et al., 1991; and Holmes, 2002).

Whilst these alternative models to the nonlinear TAR or ESTAR models also appear to provide a parsimonious fit to the data the authors did not compute the standard statistical tests for threshold nonlinearity or estimate TAR or ESTAR models. ${ }^{6}$ It seems of interest to examine the properties of some tests that a researcher would employ in reporting a parsimonious nonlinear ESTAR model, if in fact, the true DGP is generated from the alternative models. ${ }^{7}$ If the tests for parsimony of the nonlinear models have good size and power characteristics when applied to such models this would provide further evidence in support of the nonlinear adjustment mechanism, which is the only one of the competing models with a proper micro-theoretic basis. That is the purpose in this paper. We consider four different DGP's that have been proposed for modelling PPP deviations these are (a) a random walk, (b) an ARIMA(1,1,1) motivated by Engel (2000), (c) a nonstationary but mean reverting fractional process, (d) a stochastic unit root process.

The rest of the paper is organised as follows. In the next section we set out the design of our Monte Carlo experiments and discuss the findings. Section 3 reports empirical results on nonlinear models of real exchange rates in high inflation economies. The last section is a brief conclusion.

\section{M onte Carlo Experiments}

Other studies have examined the size and power of linearity tests (see Terasvirta, 1994, Luukkonen et al., 1988, and Escribano and Jorda, 1999). These studies have usually simulated general STAR processes where three main parameter values have to be calibrated, namely, the autoregressive parameters, the speed of adjustment parameter, and the variance of the noise term. However, their results are limited to processes with the characteristics described by those parameter values. In this paper, we calibrate the parameter values based on explicit ESTAR processes in the literature on PPP adjustments.

All our Monte Carlo experiments described below are based on 10,000 replications, for sample sizes of $T=360$ and $120 .^{8}$ The shocks are assumed to be

\footnotetext{
${ }^{4}$ Taylor et al. (2001) and Pippenger and Goering (1993) demonstrate that the standard Dickey Fuller unit root tests have low power against data simulated from an ESTAR model.

${ }^{5}$ For both high-inflation economies and also for bilateral real exchange rates against the US Dollar under the post war float

${ }^{6}$ Byers and Peel (2000) show that data that is generated from an ESTAR process can appear to exhibit the fractional property (as conjectured by Acosta and Granger, 1995) thus potentially providing an explanation of the results reported employing the fractional processes.

${ }^{7}$ Caner and Kilian (2001) examine the size distortions of stationarity tests within the PPP framework. However, their study assumes linear stationary real exchange rates.

${ }^{8}$ These sample sizes would correspond to available data at monthly or quarterly frequency for the post-Bretton Woods period. The actual sample size in each replication were of 1,360 and 1,120 data points, respectively. We then discard the first 1,000 data points.
} 
i.i.d. $\mathrm{N}\left(0, \sigma^{2}\right)$, where $\sigma^{2}$ is calibrated on actual magnitudes reported in the literature for monthly and quarterly estimates of real exchange rates (see Taylor et al., 2001; Kilian and Taylor, 2003; and Paya et al., 2003). All results presented are based on a 5 percent nominal significance level. We generate 10,000 artificial series given by the following DGPs:

(a) A Random Walk

$$
q_{t}=q_{t-1}+u_{t}
$$

where $q$ is the real exchange rate. $q_{0}=0$ and $\sigma_{u}^{2}=0.035$ for sample sizes of 360 and $\sigma_{u}^{2}=0.05$ for sample sizes of 120 .

(b) An $\operatorname{ARIMA}(1,1,1)$ process as postulated by Engel (2000) in his calibrated example

$$
\Delta q_{t}=\phi \Delta q_{t-1}+u_{t}-\theta u_{t-1}
$$

where $\Delta=q_{t}-q_{t-1}, q_{0}=0$ and $\sigma_{u}^{2}=0.035$ for sample sizes of 360 and $\sigma_{u}^{2}=0.05$ for sample sizes of 120 .

We set $\phi=0.95,0.8$; and $\theta=0.8,0.7$, based on the values in Engel. The different parameterization of $\phi$ and $\theta$ serve to give an impression of the size and power of the tests under different "persistence" in the real exchange rate data.

(c) A fractional process described by

$$
(1-L)^{d} q_{t}=u_{t}
$$

with $q_{0}=0$ and $\sigma_{u}^{2}=0.035$, for sample sizes of 360 and $d=0.8,0.5$.

These values of $d$ imply the real exchange rate is non-stationary but mean reverting.

(d) A stochastic unit root process based on Bleaney et al. (1999):

$$
q_{t}=\left(1+\delta_{t}\right) q_{t-1}+v_{t}
$$

where $v_{t} \sim N(0,0.0316) \quad \delta_{t} \sim N(0,0.1732)$.

We mimic the procedure a researcher might follow in determining whether data was generated from a ESTAR model of the general form

$$
q_{t}=a+\left(\beta_{1}\left(q_{t-1}-\alpha\right)+\beta_{2}\left(q_{t-2}-\alpha\right)\right) e^{-\gamma\left(q_{t-1}-a\right)^{2}}+\omega_{t}
$$

where $a, \beta_{1}, \beta_{2}$ and $\gamma$ are constants and $\omega_{t}$ is white noise. This form spans all the estimates reported in the empirical literature. For monthly data typical results reported suggest that the constraint $\beta_{1}=1, \beta_{2}=0$ cannot be rejected (see e.g. Taylor et al. 2001) and for quarterly and annual data that the constraint $\beta_{1}+\beta_{2}=1$ cannot be rejected (see e.g., Michael et al., 1997; Killian and Taylor, 2003; and Paya and Peel, 2003). Paya and Peel (2004) demonstrate that temporal aggregation of an assumed ESTAR process at the highest frequency of data generates exactly this pattern of coefficient restrictions in the great majority of simulated data. ${ }^{9}$

\footnotetext{
${ }^{9}$ The ESTAR process is of the form $q_{t}=b+q_{t-1} e^{-\gamma\left(q_{t-1}-b\right)^{2}}+u_{t}$
} 
We analyze the properties of various specification tests if a nonlinear ESTAR model is fitted to one of the four models described above. In order to do that, we follow the following procedure:

(1) First compute the LM tests for nonlinearity in the real exchange rate data, $q_{t}$. Whilst the ESTAR is suggested on theoretical criteria we compute the general nonlinearity test which includes both the ESTAR and LSTAR forms, since it is of interest for other applications. Escribano and Jorda (1999) extended the familiar nonlinearity test procedure formulated by Terasvirta (1994) and proposed a new specification strategy to choose between ESTAR and LSTAR models. This new procedure appears to be consistent and to generate much higher correct selection frequencies than that of Terasvirta (1994). We estimate the following equation:

$$
q_{t}=\delta_{0}+\delta_{1} x_{t}+\lambda_{1} x_{t} z_{t-d}+\lambda_{2} x_{t} z_{t-d}^{2}+\lambda_{3} x_{t} z_{t-d}^{3}+\lambda_{4} x_{t} z_{t-d}^{4}+v_{t}
$$

where $x_{t}=\left(q_{t-1}, \ldots, q_{t-p}\right)^{\prime}$ and $z_{t-d}$ is the transition variable, in our case equals to $q_{t-d}$, where $d$ is the delay parameter. The null hypothesis of linearity is $\mathrm{H}_{0}^{1}: \lambda_{1}=\lambda_{2}=\lambda_{3}=\lambda_{4}=0$. The computation of the test is done using the $F$ version of the test. ${ }^{10}$ Once linearity is rejected, we followed the Escribano and Jorda procedure to discriminate between models. We test the null $\mathrm{H}_{0}^{E}$ : $\lambda_{2}=\lambda_{4}=0$ with an F-test $\left(\mathrm{F}_{E}\right)$. We also test the null $\mathrm{H}_{0}^{L}: \lambda_{1}=\lambda_{3}=0$ with an $F$-test $\left(\mathrm{F}_{L}\right)$. If the minimum $p$-value corresponds to $\mathrm{F}_{L}$, we select LSTAR, otherwise, if it corresponds to $\mathrm{F}_{E}$, we select ESTAR.

When computing the LM test for nonlinearity one has to decide upon an appropriate lag length $p$ in (6). ${ }^{11}$ Various approaches can be used for this purpose, including information-based rules such as the familiar Schwarz and Akaike information criteria, and deterministic rules based solely on the sample size T. Here we use the "general-to-specific" approach proposed by Hall (1994). We do not assume that the correct lag length is known in the Monte Carlo experiments, but rather we determine the lag length for each individual series employing the general-to-specific approach. ${ }^{12}$

(2) We estimate the nonlinear ESTAR model as in (5). We then check how many times the ESTAR model would be accepted in terms of a significant speed of adjustment, $\gamma \cdot{ }^{13}$ We finally check the residual diagnostics of the estimated nonlinear model. We compute the test for autocorrelation for lags 1, 4 and 12 using the Eitrheim and Terasvirta (1996) LM test for autocorrelation in nonlinear series, and the LM test for remaining ARCH effects.

\footnotetext{
${ }^{10}$ The $\chi^{2}$ version of the test yielded similar results.

${ }^{11}$ See Terasvirta (1994) when $d$ is unknown.

${ }^{12}$ We start by a maximum number of 6 lags and the minimum lag length is one.

${ }^{13}$ Empirical marginal significance levels of the estimated parameter $\gamma$ has to be obtained through Monte Carlo simulation as it is not defined under the null. In particular, the model is assumed to follow a unit root linear autoregressive process and then a nonlinear ESTAR specification (equation 5) is estimated, computing the appropriate confidence interval of significance for $\gamma$. See Paya and Peel (2004) for a detailed description of the procedure.
} 


\subsection{Discussion of Results: Size}

Table 1 provides the simulation results. ${ }^{14}$ Each table displays three different statistics. We first consider the rejection rate of the linearity test (6) for the real exchange rate, $q_{t, \text {. }}$ Out of those cases we compute the number of times that the ESTAR model would be accepted as opposed to the LSTAR model and then express this value as a proportion of the total. From these cases, we then show the number of times (again over the total) that an estimated ESTAR model would pass all diagnostics tests. In particular, whether the estimated ESTAR model provides a significant speed of adjustment, $\gamma$, at the five percent level. In the cases that the ESTAR is considered a significant model, we then look at the diagnostic statistics for autocorrelation and ARCH effects up to twelve lags. Therefore, the last figure of the table (labelled as diagnostics) represents the proportion of times an ESTAR model would be fully accepted when the true DGP is either a Random Walk, ARIMA, fractional process or stochastic unit root process.

The size of the linearity test is slightly above nominal size for the random walk, ARIMA and fractional models and it is evident that the size distortions are slightly larger for more "persistent" processes. ${ }^{15}$ The ESTAR nonlinearity form would only be accepted around five percent of the time in these cases, matching the nominal size. Moreover, we would successfully fit an ESTAR model below three percent of the time when diagnostic tests are taken into account in these three cases. The size of the tests is not significantly different between the "monthly" case (sample of 360) or "quarterly" case (sample of 120).

The size of the linearity test is very low when the true DGP is a stochastic unit root. ${ }^{16}{ }^{17}$ In this case around sixty percent of the time we would accept an ESTAR model. However, the diagnostic statistics play a significant role in this case. The high autocorrelation in the residuals would lead us to accept the nonlinear model in some fifteen percent of the cases.

Overall these results show that linearity tests do not excessively spuriously reject the null of linear nonstationary models in small samples, especially if they are generated by a random walk, ARIMA or fractional process.

\footnotetext{
${ }^{14}$ The results reported correspond to the restricted cases where $\beta_{1}=1, \beta_{2}=0$ in the "monthly" case of samples of 360 , and $\beta_{1}+\beta_{2}=1$ in the "quarterly" case of samples of 120 . The results of the unconstrained cases are quantitatively similar and available upon request from the authors.

${ }^{15}$ See Kapetanios et al. (2003) for a new developed test for nonlinearity when processes are nonlinear STAR models. Their tests has better power than the tests used in this paper against the random walk hypothesis. However, it can only be used to discriminate between unit root and globally mean reverting STAR processes.

${ }^{16}$ We also estimated the model $Q_{t}=\left(1+\delta_{t}\right) Q_{t-1}+v$, where $q_{t}=Q_{t}-0.17 q_{t-1}$. The results were quantitatively similar to the case above and available upon request from the authors.

${ }^{17}$ Taylor and Van Dijk (2002) demonstrate that the stochastic unit root tests of McCabe and Tremayne (1995) appear to display little or no power against threshold unit root processes.
} 


\subsection{Discussion of results: Power}

To further investigate the properties of the nonlinearity tests we analyse the power of the tests. We consider another set of experiments in which the true DGP is given by the nonlinear ESTAR process (5) with $\beta_{1}+\beta_{2}=1, \gamma=\{1,2\}$, and $\sigma_{w}=\{0.035,0.05\}$. We check the power of the nonlinearity test based on the size-adjusted critical values using the previous simulation results. For each different null hypothesis we compute the size-adjusted five percent critical level and see how many times the nonlinearity test would reject linearity when the true DGP is ESTAR. Table 2 shows that the power is lower than expected, between nine and thirty percent, for the random walk, ARIMA and fractional process and is nil for the stochastic unit root case. When the size distortions of linearity tests are corrected using the appropriate finite sample critical values we observe a further loss of power.

This finding would create a problem if we believed that the real exchange rate is generated by any of the models (a) to (d) described above and linearity was not rejected by the data. In this case, we would not know whether we do not reject the null hypothesis of linearity because the model is actually a linear nonstationary process or because of the lack of power. Only in the case of a rejection of the null hypothesis can we be confident, from a statistical perspective, that the linearity test sheds light on the question of whether real exchange rate are a linear nonstationary process. ${ }^{18}$

\section{High Inflation Economies: Further Empirical Evidence}

Our Monte Carlo results show that for data simulated from a stochastic unit root process the size and power properties of the nonlinearity tests were very poor. Bleaney et al (1999) report results on the properties of real exchange rates for five high-inflation countries. They suggest that all of them do not exhibit mean reverting behavior and four of them can be described by stochastic unit root processes. Given the difficulty, from a statistical perspective, to correctly discriminate between linear stochastic unit root and non-linear globally mean-reverting processes, we report new results on the PPP deviations in high inflation economies. In Table 3 we report ESTAR specifications for four of their economies. ${ }^{19}$ The ESTAR provides a parsimonious fit to three of the data sets and has appropriately signed coefficients for another one of them. ${ }^{20}$ Given that

\footnotetext{
${ }^{18}$ Except in the case of a stochastic unit root null hypothesis.

${ }^{19}$ Data kindly provided by Michael Bleaney. Bleaney et al. (1999) reported that data for Brazil was a pure unit root process. We fit a parsimonious ESTAR process to that data set. On the other hand, they report a stochastic unit root process for Chile but we cannot fit a parsimonious ESTAR process to data for that country.

${ }^{20}$ Panel B in Table 3 provides the half-lives of shocks to the nonlinear ESTAR model using the Generalized Impulse Response Function (GIRF) introduced by Koop, Pesaran and Potter (1996) that successfully confronts the challenges that arise in defining impulse responses for nonlinear models. Taylor et al. (2001) and Paya et al. (2003) report similar estimates of
} 
Table $1 \quad$ Effective size of Linearity and ESTAR tests for the nominal 5\% level of the null of linear nonstationary process denoted below

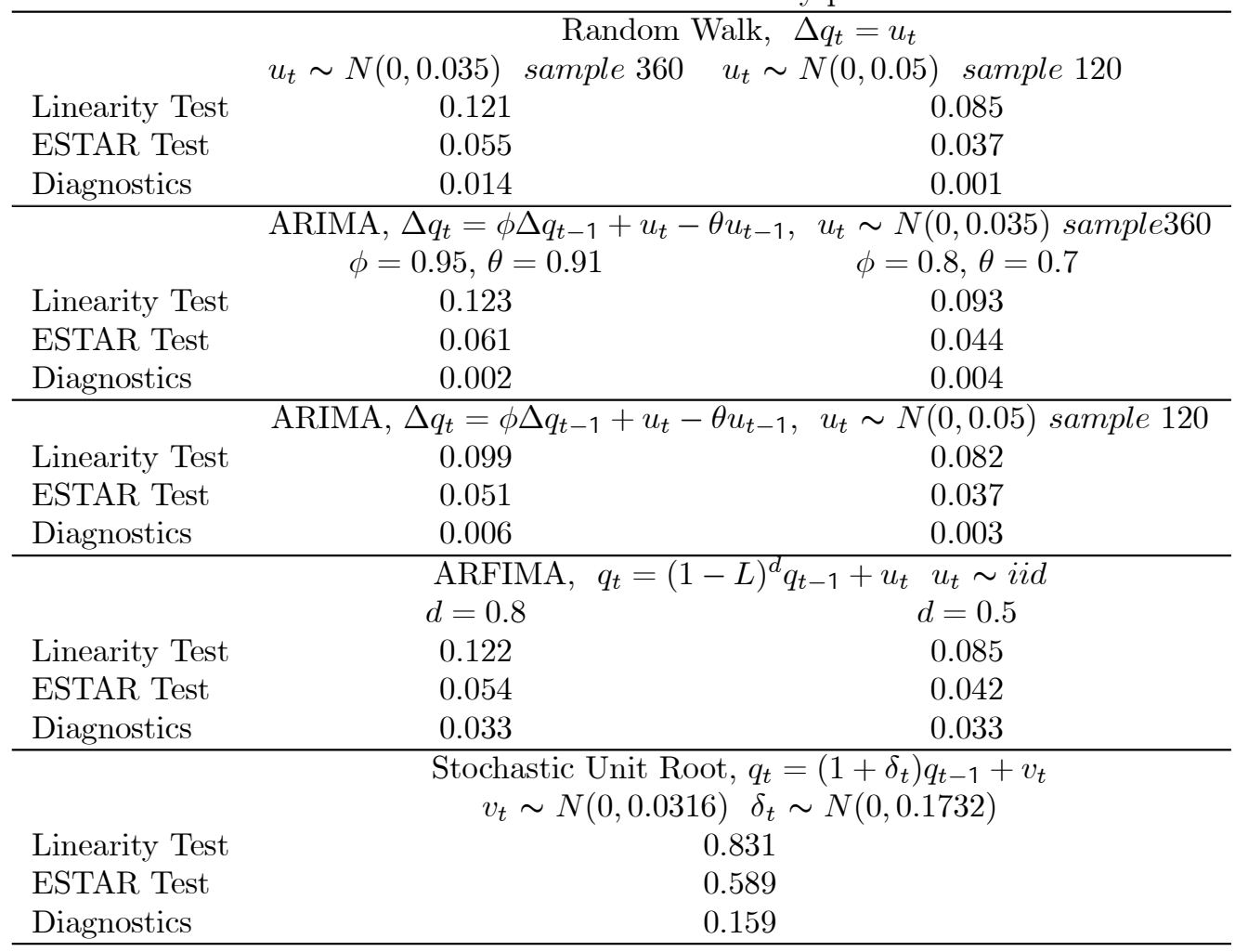


Table $2 \quad$ Power of Linearity tests of the null of ESTAR process based on size-adjusted critical values based on the following processes

\begin{tabular}{|c|c|}
\hline & Random Walk, $\Delta q_{t}=u_{t}$ \\
\hline & $u_{t} \sim N(0,0.035)$ \\
\hline Linearity Test & 0.122 \\
\hline \multirow[t]{3}{*}{ ESTAR Test } & 0.011 \\
\hline & ARIMA, $\Delta q_{t}=\phi \Delta q_{t-1}+u_{t}-\theta u_{t-1}, u_{t} \sim N(0,0.035)$ \\
\hline & $\phi=0.8, \theta=0.7$ \\
\hline Linearity Test & 0.236 \\
\hline \multirow[t]{2}{*}{ ESTAR Test } & 0.206 \\
\hline & $\begin{array}{c}\text { ARIMA, } \Delta q_{t}=\phi \Delta q_{t-1}+u_{t}-\theta u_{t-1}, u_{t} \sim N(0,0.05) \\
\phi=0.95, \theta=0.91 \quad \phi=0.8, \theta=0.7\end{array}$ \\
\hline Linearity Test & 0.162 \\
\hline \multirow[t]{2}{*}{ ESTAR Test } & 0.124 \\
\hline & $\begin{array}{c}\text { ARFIMA, } \quad q_{t}=(1-L)^{d} q_{t-1}+u_{t}, \quad u_{t} \sim i i d \\
d=0.8 \\
d=0.5\end{array}$ \\
\hline Linearity Test & 0.243 \\
\hline \multirow[t]{2}{*}{ ESTAR Test } & 0.212 \\
\hline & $\begin{aligned} \text { Stochastic Unit Root, } & q_{t}=\left(1+\delta_{t}\right) q_{t-1}+v_{t} \\
v_{t} \sim N(0,0.0316) & \omega_{t} \sim N(0,0.1732)\end{aligned}$ \\
\hline Linearity Test & 0.000 \\
\hline ESTAR Test & 0.000 \\
\hline
\end{tabular}


Table 3: Panel A: Results from ESTAR models of real exchange rate against US Dollar for high inflation economies. 1972-1993 monthly observations.

\begin{tabular}{|c|c|c|c|c|c|c|c|c|c|c|c|c|}
\hline Panel A & $\hat{\delta}_{0}$ & $\hat{\beta}_{1}$ & $\hat{\beta}_{2}$ & $\hat{\beta}_{3}$ & $\hat{\gamma}$ & $s$ & $\mathrm{Q}(1)$ & $\mathrm{Q}(4)$ & $\mathrm{Q}(12)$ & $\mathrm{A}(1)$ & $\mathrm{A}(4)$ & $\mathrm{A}(12)$ \\
\hline Argentina & $\begin{array}{l}-1.006 \\
(0.057)\end{array}$ & $\begin{array}{l}0.85 \\
(0.139)\end{array}$ & $\overline{\beta_{2}}=1-\beta_{1}$ & $\beta_{3}=0$ & $\begin{array}{l}0.40 \\
(0.15)\end{array}$ & 0.147 & 0.99 & 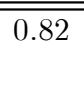 & 0.85 & 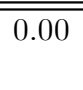 & 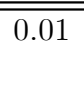 & 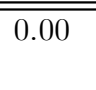 \\
\hline Brazil & $\begin{array}{l}-5.28 \\
(0.049)\end{array}$ & $\begin{array}{l}0.92 \\
(0.11)\end{array}$ & $\beta_{2}=1-\beta_{1}$ & $\beta_{3}=0$ & $\begin{array}{l}0.48 \\
(0.19)\end{array}$ & 0.046 & 0.99 & 0.68 & 0.13 & 0.13 & 0.66 & 0.76 \\
\hline Israel & $\begin{array}{l}-2.32 \\
(0.027)\end{array}$ & 1 & $\beta_{2}=0$ & $\beta_{3}=0$ & $\begin{array}{l}1.53 \\
(0.68)\end{array}$ & 0.033 & 0.36 & 0.61 & 0.75 & 0.46 & 0.93 & 0.95 \\
\hline Colombia & $\begin{array}{l}4.97 \\
(0.027)\end{array}$ & $\begin{array}{l}1.26 \\
(0.09)\end{array}$ & $\begin{array}{l}-0.03 \\
(0.13) \\
\end{array}$ & $\begin{array}{l}\beta_{3}=1- \\
\beta_{1}-\beta_{2}\end{array}$ & $\begin{array}{l}0.29 \\
(0.19)\end{array}$ & 0.011 & 0.92 & 0.55 & 0.12 & 0.01 & 0.00 & 0.00 \\
\hline Panel B & \multicolumn{4}{|c|}{ Estimated half-lives of shocks in months } & \multicolumn{4}{|c|}{ Nonlinearity Test } & & & & \\
\hline Argentina & 5 & 5 & 4 & & 0.000 & 0.006 & 0.037 & & & & & \\
\hline Brazil & 22 & 20 & 14 & & 0.016 & 0.009 & 0.002 & & & & & \\
\hline Israel & 14 & 12 & 7 & & 0.020 & 0.011 & 0.300 & & & & & \\
\hline Colombia & 47 & 47 & 27 & & 0.381 & 0.140 & 0.141 & & & & & \\
\hline
\end{tabular}

Notes: Numbers in parentheses are Newey-West standard error estimates. s denotes the residual standard error. Q(l) corerspond to the p-value of the Eitrheim and Terasvirta (1996) LM test for autocorrelation up to olag $l$. A(1) correspond to the p-value of the LM test for ARCH effects up to lag $l$. 
the ESTAR model has a theoretical rationale, unlike the stochastic unit root process, the apparent stochastic unit root property of PPP deviations in high inflation economies might reasonably be interpreted as a misleading property.

\section{Conclusions}

Recent empirical work has shown that ESTAR models, which are well motivated theoretically, provide a parsimonious empirical fit to a variety of PPP data sets. We have shown in this paper that when the null of a non-stationary linear process for the real exchange rate is rejected in favour of a parsimonious ESTAR process for the real exchange rate a researcher can be quite confident about his results given our findings on the size properties of the tests. However if the priors of the researcher are for a non-stationary linear process then the power properties of the tests reveal that non-rejection of linearity test would not be confirmation of his priors.

Overall our results provide further support for the conjecture that PPP deviations are a nonlinear mean reverting process.

nonlinear impulse response functions for bilateral and effective real exchanges at monthly frequencies for post-Bretton Woods period.

Panel B also reports the nonlinearity tests. However, the results of previous section show that those tests do not have the appropriate size and power to discriminate between stochastic unit root process and globally mean reverting nonlinear ESTAR. 


\section{REFERENCES}

Acosta, F.M. A. and Granger, C.W.J. (1995). 'A linearity test for near for near-unit root time series'. Discussion paper no. 95-12. University of California San Diego, San Diego, CA.

Anderson, H.M. (1997). 'Transaction costs and nonlinear adjustment towards equilibrium in the US Treasury Bill market', Oxford B ulletin of E conomics and Statistics, Vol. 59, pp. 465-484.

Balke, N.S., and Fomby T.B. (1997). 'Threshold cointegration', International Economic Review Vol. 38, pp. 627-645.

Berka, M. (2002). 'General equilibrium model of arbitrage, trade and real exchange rate persistence', Mimeo University of British Columbia.

Bleaney, M.E., Leybourne, S.J., and Mizen, P. (1999). 'Mean reversion of real exchange rates in high-inflation countries', Southern E conomic J ournal Vol. 65 , pp. 839-854.

Bleaney M.E.; Leybourne S.J. (2003). "Real exchange rate dynamics under the current float: A re-examination", The M anchester School Vol. 71, pp. 156171 .

Byers, J.D., and Peel, D.A. (2000). 'Non-linear dynamics of inflation in high inflation economies', The Manchester School Vol. 68, pp. 23-37.

Caner, M., and Kilian, L. (2001). 'Size distortions of tests of the null hypothesis of stationarity: evidence and implications for the PPP debate', Journal of International Money and Finance Vol. 20, pp. 639-657.

Diebold, F.X., Husteded, S., and Rush, M. (1991). 'Real exchange rates under the gold standard', J ournal of Political E conomy Vol. 99, pp. 1252-1271.

Dumas, B. (1992). 'Dynamic equilibrium and the real exchange rate in a spatially separated world', Review of Financial Studies Vol. 5, pp. 153-180.

Engel, C. (2000). 'Long run PPP may not hold after all', J ournal of International E conomics Vol. 51, pp. 243-273.

Eitrheim, O, and Terasvirta, T. (1996). 'Testing the adequacy of smooth transition autoregressive models', J ournal of E conometrics Vol. 74, pp. 59-75.

Escribano, A., and Jorda,O. (1999). 'Improved testing and specification of smooth transition regression models', in Nonlinear Time Series Analysis of Economic and Financial Data, Kluwer Academic Publishers, USA.

Hall, A. (1994). 'Testing for a unit root in time series with pretest databased model selection', J ournal of Business and Economic Statistics Vol. 12, pp. $461-470$.

Holmes, M.J. (2002). "Purchasing power parity and the fractional integration of the real exchange rate: New evidence for less developed countries", Journal of Economic Development Vol. 27, pp. 125-135.

Kapetanios, G., Shin, Y., and Snell, A. (2003). 'Testing for a unit root in the nonlinear STAR framework', J ournal of E conometrics Vol. 112, pp. 359-379.

Kilian, L., and Taylor, M.P. (2003). 'Why is it so difficult to beat the random walk for exchange rates?', J ournal of International Economics Vol. 60, pp. 85-107. 
Koop, G., Pesaran, M.H., and Potter, S.M. (1996). 'Impulse response analysis in nonlinear multivariate models', J ournal of Econometrics, Vol. 74, pp. 119-147.

Luukkonen, R., Saikkonen, P., and Terasvirta, T. (1988). 'Testing linearity against smooth transition autoregressive models', Biometrika Vol. 75, pp. 491499

McCabe, B.P.M., and Tremayne, A. (1995). 'Testing a time series for difference stationarity', T he Annals of Statistics Vol. 23, pp. 1015-1028.

Michael, P., Nobay, A.R., and Peel, D.A. (1997). 'Transactions costs and nonlinear adjustment in real exchange rates: an empirical investigation', J ournal of Political E conomy, Vol. 105, pp. 862-879.

Obstfeld, M., and Taylor, A.M. (1997). 'Nonlinear aspects of goods-market arbitrage and adjustment : Hecksher's commodity points revisited', J ournal of the J apanese and International Economies Vol. 11, pp. 441-479

O'Connell, P. (1998). 'Market frictions and real exchange rates', J ournal of International Money and Finance Vol. 17, pp. 71-95.

Ohanian, l.E., and Stockman, A.C. (1997). 'Short-run independence of monetary policy under pegged exchange rates and effects of money on exchange rates and interest rates', J ournal of Money, Credit and Banking, Vol. 29, pp. 783-806.

Paya, I. , Peel, D.A. (2003). 'Nonlinear PPP under the gold standard', Southern Economic J ournal forthcoming.

Paya, I., Peel, D.A. (2004). 'Temporal Aggregation of an ESTAR process: Some implications for PPP adjustments', IVIE Working Paper AD 2004-25. Journal Of Applied Econometrics, forthcoming

Paya, I., I.A. Venetis, and Peel, D.A (2003). 'Further evidence on PPP adjusment speeds: The case of effective real exchange rates and the EMS', Oxford Bulletin of E conomics and Statistics Vol. 65, pp. 421-438.

Pippenger, M.K. and G.Goering. (1993). 'A Note on the Empirical Power of Unit Root Tests Under Threshold Processes', Oxford Bulletin of Economics and Statistics, Vol. 55, pp. 473-81.

Rogoff, K., (1996). 'The purchasing power parity puzzle', J ournal of Economic Literature Vol. 34, pp. 647-668.

Sercu,P., Uppal,R., and Van Hull,C. (1995). 'The exchange rate in the presence of transactions costs:implications for tests of purchasing power parity', J ournal of Finance Vol. 50, pp. 1309-1319.

Taylor, M.P., Peel, D.A., and Sarno, L. (2001). 'Nonlinear mean-reversion in real exchange rates: Toward a solution to the purchasing power parity puzzles', International Economic Review, Vol. 42, pp. 1015-1042.

Taylor, A.M.R., and Van Dijk, D. (2002). 'Testing for stochastic unit roots Some Monte Carlo evidence', Oxford Bulletin of Economics and Statistics Vol. 64, pp. 381-397.

Terasvirta, T. (1994). 'Specification, Estimation and Evaluation of Smooth Transition Autoregressive Models', J ournal of the American Statistical Association, Vol. 89, pp. 208-218.

Uppal,R. (1993). 'A General equilibrium model of international portfolio choice', J ournal of F inance, Vol. 48, pp. 529-553. 